Article

\title{
Faith Resilience: Everyday Experiences
}

\section{Özlem Ögtem-Young}

Department of Social Policy, Sociology and Criminology, University of Birmingham, Birmingham B15 2TT, UK; o.young@bham.ac.uk; Tel.: +44-121-414-2703

Received: 10 November 2017; Accepted: 1 February 2018; Published: 6 February 2018

\begin{abstract}
The concept of resilience continues to be popular within various discourses and disciplines across the social and natural sciences, and has also been adopted politically and in policy. The concept's extended and widening usage in ever-increasing contexts creates further complexities and contestation on what construes resilience. Generally, in these conceptualisations, resilience is a positive outcome following significant crisis and disaster at an extreme scale. However, such definitions and constructs ignore that resilience manifests itself in subtler and more mundane ways in people's daily life and daily activities. This article explores how resilience is built into everyday life and how faith is used as a tool of resilience by individuals from diverse communities in their daily experiences in the city of Birmingham. This article contributes to the resilience literature by exposing examples of resilience as narrated during our in-depth interviews with participants (comprised of members from various new and established migrant ethnic communities), with particular attention given to faith as a form of resilience. This article argues that resilience manifests itself in the day-to-day experiences and practices of individuals and that faith can play an important role in individuals' lives in overcoming and coping with the challenges of their daily stressors.
\end{abstract}

Keywords: resilience; everyday experiences; faith

\section{Introduction}

This article aims to explore the relatively unexamined understandings of the concept of resilience that are prevalent in the day-to-day strategies and practices of people from diverse faith communities as well as ethnic and migrant backgrounds, with a particular focus on faith as a form of resilience. The attractiveness of the concept is continuously increasing, so too is the complexity and diversity of the cultural and social fabric of Western societies. As such, some authors have identified this process as being 'super-diverse' [1,2] or 'hyperdiverse' [3] to overcome the limitations of the complex conceptualisations of today's increasingly diverse societies inherent in previous accounts. Therefore, larger cities in the UK, such as Birmingham — and elsewhere-have been described as 'super-diverse'.

The challenges that such increasing diversity or 'super-diversity' —as characterised by recent new demographic and mobility patterns [1] — poses on the increasingly diverse communities living in these cities and countries are also complex and multifaceted. Some of the particular challenges that these cities now face are described as 'new patterns of inequality and prejudice'; 'new patterns of segregation'; and issues around 'transnationalism and integration' [1]. Such challenges can be part of the everyday experiences of individuals from ethnic minority communities and migrant groups, requiring them to draw resilience and coping strategies from various resources. Faith is acknowledged to be one of these resources, allowing individuals from faith communities to draw on it as a tool of resilience [4].

The concept of resilience is prevalent and adopted widely in the discourses of policymakers and policy, and is usually seen as a process or outcome which results from facing and responding to adversity in the form of extraordinary and large-scale events [5]. It suggests the ability and capacity of 
systems, organisations, individuals, cities, communities, or societies to 'bounce back' and be able to maintain their core functioning; adapting positively in the face of a straining or adverse condition $[6,7]$. Although much of the discussion and conceptualisation of resilience in policy, as well as in the scholarly canon, has mainly revolved around this extraordinary nature of resilience, it is far from fixed and static; it arises not only in the face of significant adversity but is embedded in the ordinary everyday activities and challenges people encounter, a fact which is mostly overlooked in the scholarly canon [8].

This general lack of focus on the fluid and subjective nature of resilience ignores the significance of recognising the multiple ways and specific cultural contexts in which resilience is realised and constructed by individuals. Therefore, an investigation of this fluid and subjective nature of the concept is timely and policy-relevant [9]. Based on 18 in-depth, semi-structured interviews, this article explores ordinary practices of resilience in the daily life of individuals and their communities, and how faith is used as a form of resilience. In this research, imposing a definition of the concept was avoided; instead, researchers allowed participants to reveal their experiences of resilience in everyday contexts through personal perceptions and interpretations of the phenomenon, thereby exploring the relatively unexamined understandings of resilience that are prevalent in day-to-day life. This article argues that resilience is not limited to the process or outcome of extreme events but that it also manifests itself in daily struggles and difficulties which are specific to individuals' lives and communities. This research focuses not only on established migrant communities but also on members of newer, smaller, less organised community groups with various legal and migrant statuses in order to reflect the nature of today's super-diverse cities in Britain.

\section{Resilience in the Literature}

The concept of resilience has been used widely and extensively across many disciplines including engineering, ecology, biology, and psychology. While engineers apply it to the speed and ability of a material to return to its original state after pressure, ecologists refer to resilience as the ecosystem's capacity to adjust to a new condition brought about by a change while preserving its core functions-this usage was first used and defined within ecology by Holling [10,11]. Resilience has particularly been a potent and long-studied theme within psychology, applied to a person's capacity to cope with, and emerge stable from, experiencing traumatic incidents. Nevertheless, this short, overarching definition does little justice to the highly disputed and contested nature of the concept existing within the field of psychology, so much so that some psychologists suggest abandoning its use altogether, as they believe these myriad definitions have led to ambiguity and obscurity, making it a meaningless concept [12] (p. 15).

Research and debates around the resilience phenomenon within psychology have had an enormous impact on the development and spread of the concept within other fields in the social sciences; most definitions have their roots in these disciplines [13] (p. 155). Given this, it is important to include debates that exist within these disciplines. In broad terms, one of the primary sources of disagreement has been over the nature of resilience and the factors that contribute to it. For example, one of the divides amongst resilience researchers and theorists is whether it is a product of personality traits [14] or the result of 'protective factors' and 'compensatory factors' [15]. Others argue over the nature, level, impact, and role of important concepts associated with resilience, such as 'vulnerability', 'risk', 'adversity', 'adaptation', and 'coping'. Another issue of concern is whether resilience is an outcome or a process, placing different emphasis on the end result when encountering stressors, traumas, or disastrous life events. They all have their limitations and are discussed extensively by researchers (see, for example, [13] for comprehensive details of the weaknesses of each debate).

One of the main criticisms of these debates has come from the fields of social work and sociology, which criticise conceptualisations of resilience as not accounting for subjective interpretations of the phenomenon by subjects themselves. These constructivist perspectives draw attention to the role of human agency in perceptions and constructions of resilience, and to the context within which individuals negotiate and mediate their positions and understanding of the world. For example, 
Bottrell provides a critique of 'individual and developmental' approaches to resilience and argues for the vital roles that collective experiences and social identities play in resilience [16]. The author draws her evidence from investigations into the experiences of a group of disadvantaged, stereotyped young people in Sydney, focusing on their interpretations of constructions of resilience; based on these understandings, policymakers and practitioners would make more effective interventions. Such approaches are important as they account for 'cultural practices, social processes, social change and the nature of individual-social relations' that are important to understanding the concept of resilience [16] (p. 322).

The concept of resilience has also been extended and popularised within other fields in social sciences and applied to entities such as communities, societies, nations, and cities, with particular attention paid to securitisation. The term was used in this context for the first time by Aoron Wildavsky [17], who argued for the enhanced capacity of societies-through politicians and policymakers-to enable them to cope with, and adapt to, unexpected adversity rather than focusing on preventive and protective strategies. Wildavsky saw resilience as the fundamental notion to compensate for the shortcomings of a system then under threat from the consequences of the Cold War. Since Wildasky, resilience has become an increasingly important concept in securitisation policy and practice-particularly after the events of $9 / 11$ [18].

Resilience has indeed become the buzzword of policymaking since the $9 / 11$ and $7 / 7$ bombings in London. It has provided the potential to fill the gaps in effective emergency and risk planning when dealing with extraordinary and devastating events brought about by these new forms of international terrorism, which have hugely impacted on and strained authorities' coping systems and strategies. In other words, Post 9/11 metaphors of resilience have been used to describe how cities and nations attempt to 'bounce-back' from disaster, and to describe the embedding of security and contingency features into planning systems' [19] (p. 396). Not only is this popularity a result of the terrorist attacks of $9 / 11$ and the subsequent bombings in major European cities, as other trends and patterns in the current context of globalisation have also contributed to the widened and extended usage of resilience within many areas of policy-including particular challenges posed by climate change, environmental disasters, and increased immigration [20] (p. 1).

Resilience, in these contexts and in its broadest terms, refers to the competence of institutions, communities, or societies to spring back from and adapt positively in the face of considerable adversity [21-23]. In this sense, resilience is mostly conceptualised in terms of the threat of, and vulnerability to, high-risk situations, disasters, and crises of any sort with potentially devastating consequences for members of modern societies. These potential threats at a grand scale require individuals, communities, and cities to be resilient as risk and danger cannot be diminished through the protective and preventive measures of governments and policymakers. These studies have their strengths, but they fail to recognise the concept of resilience as being fluid and part of everyday life; a concept which people utilise from various sources in multiple ways and contexts. This article builds on and contributes to the scholarly work on everyday resilience.

This brief, broad overview of the resilience literature and the consideration of its contested debates over what constitutes and contributes to the construct of resilience enhances our understanding of the concept, which will continue to evolve and be disputed. These definitions suggest that resilience is usually a positive process or outcome after exposure to disastrous life events and traumas; as a result, it is mostly defined and understood in relation to extraordinary, devastating, and highly uncertain conditions, and mostly the attention has been focused on communal resilience. It is, however, crucial to understand how faith-based resilience is manifested and built into everyday experiences, with a focus on individual level resilience. In doing so, this research contributes towards filling this gap and exposes multiple ways in which resilience is understood and experienced. As Ryan points out, the existing debates about the nature of resilience 'dislocate it from the everyday practices of communities' [24] (p. 299). I argue that these debates also disconnect it from the daily experiences of individuals, which is the focus of this article. 


\section{Faith Resilience in Everyday Life}

A substantial and growing body of research has been undertaken on various aspects and elements of faith in the resilience of individuals and communities within adverse contexts. This research mainly focuses on mental health [25,26], family relations [27,28], children and young people [29,30], and aging [31,32]. These studies have shown that faith plays a positive role in resilience building: utilising faith for meaning-making and framing of events contributed to the enhanced ability of individuals to deal with major negative life situations. Faith is called upon by individuals to provide them with a sense of control and an understanding of their stressful situations, positively contributing to the protection of their identities and positive sense of self [32-34].

Manning also identified three constituents of resilience that arise from faith which function as mechanisms in supporting and maintaining wellbeing [32]. The components of such resilience were 'having divine support, maintaining purpose, and expressing gratitude' [32] (p. 352), which promote resilience and the maintenance of a good quality of life. Although Manning and others recognise the multidimensional nature of resilience, the focus is mainly on the role of faith in promoting and being a source of resilience concerning traumatic life events or extraordinary events, such as dealing with and recovering from cancer or the challenges of old age. In such understandings the focus is on the 'static inner characteristic' rather than viewing it as an ongoing process which is part of people's everyday lives [8].

Alongside this positive facet of faith in building resilience against traumas and traumatic life events, there is also research that points out the unfavourable aspect of faith $[35,36]$. These scholars have shown that it can also have a negative impact on resilience: it may have the potential to increase levels of fear, anxiety, or stress when perceptions and understandings of faith (and religion) rest upon negative feelings and beliefs. While understanding that some elements of faith may impact negatively on resilience is essential, it is also vital to recognise that faith 'serves a distinct and compelling role in resilience' [31].

Although these studies have contributed to conceptualisations and understandings of the role of faith in resilience building, they primarily investigated the resilience phenomenon in relation to major life events $[37,38]$. It is therefore important to have more non-exclusive conceptualisations of resilience which encapsulate and account for everyday experiences of it and include non-Eurocentric perspectives. It is vital to take into account inequality, power, social relations, and individual identity $[9,16]$. Therefore, our research focuses on how resilience is built into the day-to-day experiences and practices of those who come from minority ethnic communities with diverse social, cultural, religious, and economic backgrounds and different immigration statuses. Consequently, this research is unique in its focus on the faith and everyday manifestations of resilience and in that it draws its participants from a number of religious, faith-based communities in Birmingham, a city renowned for its diversity. As Lenette et al. argue, resilience is 'situated in everydayness', in daily routines, and it is necessary to recognise that resilience does not only belong to the realm of adversity nor is it an ability of only a few [8] (p. 3).

One caveat needs to be noted: the concepts of faith and religion are complex and subjective. Although they are related concepts, they are usually seen as separate constructs-although the demarcation between these terms is not clear or definite. They are commonly used interchangeably, which was the case in the accounts of the participants. However, for the purposes of research and analysis it is important to distinguish them-it is also important due to the fact that participants' identifications with religion, and the role it plays in their lives, differed greatly and was vague at times despite the fact that they draw on some level of spirituality from their faith, and consequently a sense of strength, in coping with the difficulties and challenges they faced in their everyday lives.

Taking into account the existence of a multiplicity and diversity of practices and interpretations of religion and the continuous contradictions and negotiations experienced by individuals in terms of their religious beliefs and practices, faith is preferred as the focus of this study. As Allen notes, Faith is more fluid, more vague and ultimately, less contentious also. Faith allows for the complexities and 
negative attributions of religion to be subsumed within a more positive frame [39] (p. 271). Moreover, faith is a term that is more able to reflect 'the growing numbers defining their own sense of spirituality away from specific religious traditions' [40]. In addition, faith is seen to be somewhat more individual and personal, whereas religion is largely understood as being collective and formalised.

\section{Methodology}

\subsection{Research Setting}

Increased diversity — or 'super-diversity' — has led to an ever-growing number of encounters with different faiths, cultures, and traditions which were previously alien or unfamiliar to Western societies [41] (p. 607). This is particularly true for cities similar to Birmingham, from where research participants were drawn from a variety of migrant and ethnic minority groups. Organisational and political representations of communities and their faith and religions at the community and national level are also increasing, as is their role in policy design and implementation. Therefore, it is important to understand individuals' relationships with their faith and how it influences their ability to cope with and overcome struggles and stressors in everyday life. This study set out to do just this by conducting interviews in settings chosen by the participants themselves. Most participants preferred to meet in public places such as cafes, churches, or libraries, although a small number of participants $(n=5)$ preferred to meet in their homes as they needed to care for their children.

The context of this research is faith resilience that manifests itself in the everyday lives of individuals who have been affected by the processes of asylum and immigration policy and practice, resettlement, and discriminatory 'race' and ethnic relations. All participants were interviewed by the same researcher, who herself is a migrant from Turkey. It is widely acknowledged that 'people tend to gravitate toward those with whom they share some level of commonality' [42] (p. 4). Such gravitation was visible where participants from similar backgrounds showed more ease and comfort when reflecting their experiences. The researcher's background and position inevitably has a role in the production of the qualitative data as well as in analysis - the level of the impact this may have had on the ways in which participants answered the questions is hard to gauge, but the process of providing a full explanation, following ethical standards and explicitly outlining the reasons for the research and its use, helped participants who might have been suspicious or prejudiced at the beginning to feel at ease and more open.

\subsection{Research Design}

This research aimed to reveal the embeddedness of resilience in everyday practices and how it is experienced in subjective and various ways, with attention on faith as a source of resilience. It did so by exploring everyday manifestations of faith resilience through the analysis of data generated from in-depth, semi-structured interviews with 18 participants. An average interview lasted approximately an hour. All interviews were recorded and transcribed fully. The data emerging from these interviews was analysed using the NVIVO software package to identify research categories and themes to uncover how resilience is built in their daily encounters with struggles and stressors. This qualitative research design provided an appropriate method to explore resilience from participants' perspectives without imposing a definition of the phenomenon. The researcher allowed participants to give their accounts as they associate them with resilience, particularly those emanating from their faith. This also facilitated the self-expression of intimate and sensitive issues [43].

Participants were identified using a purposive sampling approach, which involves using the research objectives to determine who needed to be contacted and interviewed on the basis of their willingness to share their experiences and knowledge $[44,45]$. The researchers started the identification process by contacting key individuals and organisations already known to them. This included using representatives of key community organisations and various institutions working with and supporting ethnic and migrant communities, refugees, and asylum seekers in Birmingham as well as through other 
contacts within West Midlands Police, schools, and faith-based institutions. The snowballing technique was also used in identifying and recruiting participants when necessary and where possible. After the identification process, the recruitment of participants involved an assessment of their readiness and willingness to be interviewed. The process of recruiting participants was at times hard and took longer than anticipated as some of the people and organisations contacted felt uncomfortable or ambivalent towards the prospect of taking part in a research project given their vulnerable situations, such as uncertainties and fears experienced during the process of asylum claims and immigration procedures [46]. It is also notable that participants engaged were drawn from 'hard to reach' communities.

The profiles of the interviewees are detailed in Table 1 below. Eighteen people in total took part in the research, 11 of whom were male and seven of whom were female. Participants were from diverse cultural, ethnic, and socioeconomic backgrounds with different immigration statuses, all living in Birmingham. The majority $(n=13)$ of participants were born in their country of origin. The rest of the participants $(n=5)$ were born in the UK and identified themselves as being from Pakistani communities. Participants' ages varied between 25 and 63. Most of our interviewees had occupations-part-time and full-time-or were in business in a variety of areas, apart from two of the participants who did not have a job: one was a retired civil servant, and one was a housewife. All interviews were anonymised and all participants were attributed pseudonyms.

Table 1. Participant profile.

\begin{tabular}{cccccc}
\hline Pseudonym & Gender & Religion & Country of Origin & Ethnicity & Age (Years) \\
\hline Dalir & Male & Christian (convert) & Iran & Persian & Early 60s \\
Anahita & Female & Christian (convert) & Iran & Persian & Early 20s \\
Jirair & Female & Christian & Iran & Armenian & Late 40s \\
Azaduhi & Female & Christian & Iran & Armenian & Mid-30s \\
Nahor & Male & Mandaean & Iraq & Arabic & Early 50s \\
Tavis & Male & Mandaean & Iraq & Arabic & Early 40s \\
Fayaz & Male & Muslim & Iraq & Kurdish & Mid-30s \\
Ahmad & Male & Muslim & Iraq & Kurdish & Mid-20s \\
Hameed & Male & Muslim & Iraq & Arabic & Early 30s \\
Selim & Male & Muslim & Turkey & Turkish & Late 20s \\
Tahir & Male & Muslim & Turkey & Turkish & Mid-30s \\
Zara & Female & Muslim & Pakistan & Pakistani & Early 30s \\
Saba & Female & Muslim & Pakistan & Pakistani & Early 40s \\
Anam & Female & Muslim & Pakistan & Pakistani & Late 30s \\
Mehwish & Female & Muslim & Pakistan & Pakistani & Early 40s \\
Hamid & Male & Muslim & Pakistan & Pakistani & Late 20s \\
Vazir & Male & Muslim & India & Indian & Mid-40s \\
Faiq & Male & Muslim & Azerbaijan & Azerbaijani & Late 30s \\
\hline
\end{tabular}

The participants also held diverse religious beliefs, reflecting the diversity of Birmingham. Twelve participants described themselves as being Muslim, four as Christian, and two as belonging to Mandaeanism (also known as Baptism) —an ancient monotheistic religion that exists to the present day in the region of Iraq and Iran [47,48]. Both of our Mandaean participants were refugees from Iraq. Members of Mandaeanism have been forced to flee to Western countries following the disturbances and conflicts in the Middle East since 1979, and this accelerated with the more recent troubles in the region after the occupation of Iraq following the 9/11 terror attacks. The majority of the followers of this religion have sought refuge and formed diasporic communities mainly in Sweden, Canada, the USA, and Australia; there are also a few hundred living in other countries in Europe [49] (p. 217); [50]. There are very few Mandaeans living in the UK: a handful of families in Birmingham, with relatively larger communities formed in London and Manchester. Given that 
very few families live in Birmingham and, in fact, in the whole of the UK, the researcher especially appreciated being able to identify and interview the members of this ancient religion.

\section{Research Findings and Discussion}

The findings are presented and discussed under three thematic headings which emerged from the interview data and which resonate with themes in the existing body of literature about resilience among minority communities: adjusting to a host country; dealing with separation and parting; and dealing with issues of discrimination and exclusion. These were identified through conducting a thematic analysis. All the themes reflect the conditions in which participants talked about the resilience that emanated from their faith in everyday contexts.

\subsection{Adjusting to a Host Country}

Literature dealing with issues around minority groups and immigrants-particularly asylum seekers and refugees-documents in detail the challenges and struggles they faced when settling in a new country. The process of adapting to new settings and adjusting to unfamiliar and complex systems and structures and living with contrasting elements of the dominant culture requires constant negotiation, adjustment, and negotiation [51]. Faith played an important role in coping with uprooting and the loss of familiar structures and environments in some of our participants' lives. Overcoming the issue of displacement and adjustment was harder for immigrants who had settled in Birmingham with no clear and definable existing community structures, and faith seemed to serve as a source of 'hope' and 'resilience' in everyday contexts, which was expressed very starkly in the words of one of the participants:

"There are lots of challenges of course ... I will tell you something: if I take you now and put you in the middle of Iraq and tell you 'okay, do whatever you want' then you don't know how to start, you don't know your way. You are lost, and that is how we feel. We feel we are lost ... you take a tree from a place and put it in another place. It feels strange. So that is why I say the problem with Iraqis is difficult really. ... It [Iraq] was a beautiful country we had ... lots of money and you could have built yourself a lot easier than here. But what happened to all of us was that someone took us and threw us. And it is very, very hard ... Our faith helped us to survive until this moment because if you imagine someone came from these countries like the Middle East where all of these problems happened to [them] and [they] still have hope ... And that is what comes from this religion." (Nahor, Mandaean)

Although faith was identified as playing an important and central role in most participants' individual lives and in their communities, it was not seen as being the primary community marker for all participants interviewed; there were many other complex factors identified as influencing the level and nature of adherence to their community faith and how it shapes them as individuals-structural factors such as economic background, culture, education level, immigration and settlement status may have had more influence in the way in which these individuals identify themselves with other members of the society-it was not necessarily based on faith.

One interviewee described himself as liberal and as having faith, but also said that his faith had a limited effect on shaping his life. It can, therefore, be noted that participants-despite being a from relatively similar region, faith, or culture-still hold many differences and variations in their attitudes to faith and its role in forming their identities and how they utilise it as a form of resilience against their struggles. In other words, their life choices are influenced both by their social environment and individual preferences in a given context. However, this research demonstrated that faith was still part of participants' lives, no matter how diluted it appeared, as all talked about the existence of times when they turned to their faith to build resilience in the face of daily difficulties and stressors. This was very clearly articulated by one of our participants: 
"I do not always act upon my religion's requirements but in my head it defines me and defines who I am-always at the back of my mind. It gives a sense of community, cohesion, belonging, and togetherness and makes you feel you are not on your own in an environment which is hostile at times. I think for me, personally, when I do something good I know I would be rewarded." (Selim, Muslim)

Another participant explains his relationship with his faith:

"Because we are in a different country and we are lonely ... and although I do not believe in religion, there are times you pray to the God, and your pain goes away... Just like being patient and resilient; these things are in the religion; they come from the God." (Jirair, Christian)

The participant's reflections suggest contradiction in her own experience with her religion. While it was clearly expressed in her account that her faith still was an important element of her communal identity, at an individual level it was not the focus of her life, as such she described herself as not believing in religion. At the same time, her faith was still seen as providing her with a source of resilience through practising some aspects of it. This finding can be seen as a reflection of the diversity of understanding of faith, religion, and religiosity which is fluid and "so complex and personal" [52] (p. 24).

\subsection{Dealing with Separation and Parting}

The embeddedness of resilience in everyday struggles was also evident when participants talked about their experiences of separation and loss and ways of dealing with associated feelings. This was a particularly reoccurring theme for immigrants and refugees who had settled in the UK more recently. This does not come as a surprise: leaving loved ones behind or dealing with the loss of their relatives or friends while away was one of the struggles they faced, and the participants turned to their faith as a way of maintaining their well-being and coping with associated negative feelings. As one of the Kurdish participants puts it:

"[Y]our sister, brother, mum, and dad, they are all away from you ... it is difficult ... [But] when I pray, I do not think about anything". (Fayaz, Muslim)

Similarly, another interviewee emphasises the role of her faith in overcoming his daily struggles around separation and not having family support:

"Something happens back home that worries me or about my work, my daughter then I call my priest, or I go to the church and pray; my faith helps me to deal with the everyday difficulties I face." (Anahita, Christian)

The link between faith and resilience was demonstrated in our participants' narratives on numerous occasions while speaking about experiences of loss, illness, and separation from the family-for a long or short time and various reasons. This link has also been shown by several other studies [53-55] which underline the positive role of faith in coping with life events and stressors. It was clear from the participants' accounts that faith provided them with a framework of meaning and helped them to make sense of their situation regardless of the size, scale, or level of difficulty they faced in their everyday lives:

"Two, three years ago, that time my passport was not ready, and I was really missing my parents, family ... I went to the church and sat there, and I could not control myself, and I prayed: 'please, it, my passport, is not for me, it is for my parents. I don't want to go anywhere I just want to see them." (Azaduhi, Christian) 
For example, one of the participants described a time when she was admitted to hospital for several weeks as a result of the complications with her pregnancy:

"[T]hat was very hard because all my other three older kids were at home and I was just stuck there [in hospital]. And that was quite difficult because I knew it would be so much better for them if I were here [at home], but I also knew at the same time I had to stay in hospital because otherwise there was a risk to the baby. So I had to get strength from my faith just to get through those four weeks without going crazy." (Saba, Muslim)

For the interviewee, resilience involved searching her faith to find the strength to accept her situation and cope with her brief separation from her children. This relatively short separation from her children and her home required a coping mechanism which was drawn from her faith. Her account revealed another manifestation of resilience through faith as used in various everyday contexts and situations.

\subsection{Dealing with Issues of Discrimination and Exclusion}

Another major issue that our participants identified was that of incidents of harassment and exclusion encountered in everyday life. These concerns were raised more commonly amongst our Muslim participants. Reflecting the existing literature [56-58] on the new forms of racism-that is covert, subtle, and not on the basis of skin colour but faith or ethnic, cultural identity-most talked about the times and events when they felt they were under threat because of their faith and culture; many references were made to $9 / 11$ and $7 / 7$ as the key moments of facing discrimination. They expressed their concerns that various attacks on their communities came from multiple directions-particularly with the media and politicians as the main agent of othering and disseminating exclusionary discourses around Muslims. These were also the moments in which our Muslim participants described how they used their faith to deal with the difficulty of the heightened focus on their community. One of the female participants expressed how she and some members of her community used some markers of their faith to strengthen their communal identity and as a way of dealing with the situation:

"When the 9/11 happened, I think, a lot of people felt stronger in their faith, even there was kind of a backlash especially through the media against Islam and the way Muslims behave. Rather than turning away, I found that since then Muslims became stronger in their faith, and since then a lot of women started wearing scarves, and I did as well as a form of identity to be resilient; to stand up and be counted as Muslim rather than to shy away from it." (Anam, Muslim)

Related to the issue of discrimination was the feeling of the 'non-acceptance' of minority groups by the wider society. The complex nature of a sense of belonging and the sense of not being accepted by the majority were particularly expressed by those participants who were born in or came to the UK at a very early age. They saw themselves as belonging to this country but, at the same time, they expressed their concerns about the negative attitudes of the wider society around their ethnicity, culture, and belonging to the UK and 'Britishness':

"Someone like me who go on holidays and when I come back I feel here is home to me, but the majority do not feel that I belong to this country; I do not feel I belong to Iraq! I want to feel wider society see that I belong to here ... when I go to work, for example, I hear things that make me feel that I am a minority and reminded I do not belong to this country. It makes me angry to hear this divisive, anti-Muslim language." (Hameed, Muslim)

Discriminatory practices and behaviours against a specific minority group or individual because of their faith, race, or ethnicity were not just something that came from wider society: exclusionary 
behaviour towards a member of a minority group by another member of a minority group was also described in our interviews. Vertovec identifies that the new forms of immigration have also created new patterns of inequality and prejudice as well as constructions of otherness [1] (p. 1045). For example, one of the participants talked about her experiences of this nature: the participant's experiences resulted from describing herself as a Christian person who is from Iran within a Muslim group or individuals in various situations. This suggests that her identification as a Christian person from Iran did not fit in with assumptions of people who equate a certain faith with a certain race or nationality, consequently creating prejudice and discrimination against her. Her account demonstrated that her faith was a remedy when feeling low and sad due to her everyday encounters with discriminatory language directed towards her religious affiliation:

"I do have a fear in here in saying that I am Christian as an Iranian person. I get very negative reactions and sometimes insults from Muslim people for being a Christian person from Iran ... at work, my daughter's school ... I always feel I am left out and judged. My faith really helps me and makes me resilient; because every time I have a problem like this, I go to church to pray and talk to my priest. It is very helpful." (Anahita, Christian)

Discrimination and/or other social inequality based solely on ethnicity and race or faith can be part of everyday life for some members of minority groups in various forms and contexts [59]. These moments can be intensified by a single event and serve as an ongoing reason for continued exclusion and discrimination, as expressed in the accounts of some of the participants, and can manifest at individual, cultural, or institutional levels. Such discrimination and exclusions can be ongoing, subtle, and indirect [60] and as a result can be difficult to talk about, or in some cases identify, but still result in feelings of fear, sadness, and worry [59]. However, individuals who cope with discrimination through direct or indirect ways such as sharing and talking about their situations maintain a better mental and physical health than those who did not take any action [61] —as illustrated by the participant who sought solace in going to her church and talking to her religious leader.

\section{Conclusions}

Contrary to most of the literature connecting and discussing resilience in relation to adversity which is significant and devastating in scale, this study focuses on manifestations of resilience in the form of overcoming, coping, and recovering from the difficulties of daily challenges. While this general tendency within both the literature and policy frameworks to associate resilience to the responses and recovery of individuals and communities from highly risky, traumatic, and devastating life encounters is common, this study argued that resilience is relational, subjective, and contextual $[16,62]$. It also recognised the importance of how it is built into everyday experiences [8] and how faith is used to draw upon resilience when dealing with routine and daily challenges of life among faith communities. Therefore, this research is unique in its attempt to uncover faith resilience in everyday life and to reach out to both the members of established and emergent diverse communities that make up the contemporary fabric of super-diverse cities like Birmingham.

This article's findings showed how participants used their faith as a source of resilience in encounters with discrimination and exclusion, daily difficulties in settling and adjusting to a country of migration, and dealing with emotions of separation and parting - events which can be part of the everyday lives of individuals from refugee and asylum-seeking groups or other migrant communities. Although participants' identifications, affiliations, and relationships with a particular faith were reported to exist in varying degrees and to take many forms, faith as a coping mechanism was reported by all of them to be utilised as they navigated their daily lives, albeit in complex and multiple ways. This research-as previous studies have also evidenced-once again shows that being resilient does not just constitute individuals' extraordinary capabilities in the face of unusual events or that some individuals and communities just lack resilience [63], but that it is part of everyday life and manifests itself in diverse contexts. This, in effect, can inform and help policymakers to incorporate a multiplicity 
of factors and manifestations of resilience into their policies for better and more efficient outcomes, as well as to avoid top-down applications and practices.

Acknowledgments: This research received no specific grant from any funding agency in the public, commercial, or not-for-profit sectors.

Conflicts of Interest: The author declares no conflict of interest.

\section{References}

1. Vertovec, S. Super-diversity and its implications. Ethn. Racial Stud. 2008, 30, 1024-1054. [CrossRef]

2. Phillimore, J. Refugees, Acculturation Strategies, Stress and Integration. J. Soc. Policy 2011, 40, 575-593. [CrossRef]

3. Miyares, I.M. From Exclusionary Covenant to Ethnic Hyperdiversity in Jackson Heights, Queens. Geogr. Rev. 2010, 94, 462-483. [CrossRef]

4. Alawiyah, T.; Bell, H.; Pyles, L.; Runnels, R.C. Spirituality and Faith-Based Interventions: Pathways to Disaster Resilience for African American Hurricane Katrina Survivors. J. Relig. Spiritual. Soc. Work Soc. Thought 2011, 30, 294-319. [CrossRef]

5. DiCorciaa, J.; Tronick, E. Quotidian resilience: Exploring mechanisms that drive resilience from a perspective of everyday stress and coping. Neurosci. Biobehav. Rev. 2011, 35, 1593-1602. [CrossRef] [PubMed]

6. Masten, A.S. Ordinary magic: Resilience processes in development. Am. Psychol. 2001, 56, 227-238. [CrossRef] [PubMed]

7. Luthar, S.S.; Cicchetti, D. The construct of resilience: Implications for interventions and social policies. Dev. Psychopathol. 2001, 12, 857-885. [CrossRef]

8. Lenette, C.; Brough, M.; Cox, L. Everyday resilience: Narratives of single women with children. Qual. Soc. Work 2012, 12, 637-653. [CrossRef]

9. Ungar, M. Resilience across cultures. Br. J. Soc. Work 2008, 38, 218-235. [CrossRef]

10. Holling, C.S. Resilience and Stability of Ecological Systems. Annu. Rev. 1973, 4, 1-23. [CrossRef]

11. Folke, C. Resilience: The emergence of a perspective for social-Ecological systems analyses. Glob. Environ. Chang. 2006, 16, 253-267. [CrossRef]

12. De Bruijne, M.; Boin, A.; van Eeten, M. Resilience: Exploring the concept and the meaning. In Designing Resilience: Preparing for Extreme Events; Comfort, L.K., Boin, A., Demchak, C.C., Eds.; University Pittsburgh Press: Pittsburgh, PA, USA, 2010.

13. Shaikh, A.; Kauppi, C. Deconstructing Resilience: Myriad Conceptualizations and Interpretations. Int. J. Arts Sci. 2010, 3, 155-176.

14. Wagnild, G.M.; Young, H.M. Development and Psychometric Evaluation of the Resilience Scale. J. Nurs. Meas. 1993, 1, 165-178. [PubMed]

15. Luthar, S.S.; Cicchetti, D.; Becker, B. The construct of resilience: A Critical Evaluation and Guidelines for Future Work. Child Dev. 2000, 71, 543-562. [CrossRef] [PubMed]

16. Bottrell, D. Understanding 'Marginal' Perspectives: Toward a Social Theory of Resilience. Qual. Soc. Work 2009, 8, 321-339. [CrossRef]

17. Wildavsky, A. Searching for Safety; Transaction Publishers: New Brunswick, NJ, USA, 1988.

18. Coaffee, J.; Fussey, P.; Moore, C. Laminated Security for London 2012: Enhancing Security Infrastructures to Defend Mega Sporting Events. Urban Stud. 2011, 48, 3311-3327. [CrossRef]

19. Coaffee, J. From Counterterrorism to Resilience. Eur. Leg. 2006, 11, 389-403. [CrossRef]

20. Boin, A.; Comfort, L.K.; Demchak, C.C. The rise of resilience. In Designing Resilience: Preparing for Extreme Events; Comfort, L.K., Boin, A., Demchak, C.C., Eds.; University Pittsburgh Press: Pittsburgh, PA, USA, 2010.

21. Bonanno, G.A. Resilience in the Face of Potential Trauma. Curr. Dir. Psychol. Sci. 2005, 14, 135-138. [CrossRef]

22. Cutter, S.L.; Barnes, L.; Berry, M.; Burton, C.; Evans, E.; Tate, E.; Webb, J. A place-based model for understanding community resilience to natural disasters. Glob. Environ. Chang. 2008, 18, 598-606. [CrossRef]

23. McAslan, A. Community Resilience: Understanding the Concept and its Application. Torrens Resil. Inst. 2011, 1-15. Available online: http:/ / www.flinders.edu.au/centres-files/TRI/pdfs/understanding\% 20community\%20resilience.pdf (accessed on 18 April 2017). 
24. Ryan, C. Everyday Resilience as Resistance: Palestinian Women Practicing Sumud. Int. Political Sociol. 2015, 9, 299-315. [CrossRef]

25. Davydov, D.M.; Stewart, R.; Ritchie, K.; Chaudieu, K. Resilience and Mental Health. Clin. Psychol. Rev. 2010, 30, 479-495. [CrossRef] [PubMed]

26. Jonker, L.; Greeff, A.P. Resilience Factors in Families Living with People with Mental Illness. J. Commun. Psychol. 2009, 37, 859-873. [CrossRef]

27. Walsh, J. Children's understanding of mental ill health: Implications for risk and resilience in relationships. Child Fam. Soc. Work 2009, 14, 115-122. [CrossRef]

28. Rounding, K.; Hart, K.E.; Hibbard, S.; Carroll, M. Emotional Resilience in Young Adults Who Were Reared by Depressed Parents: The Moderating Effects of Offspring Religiosity/Spirituality. J. Spiritual. Ment. Health 2011, 13, 236-246. [CrossRef]

29. Gunnestad, G.; Thwala, S. Resilience and religion in children and youth in Southern Africa. Int. J. Child. Spiritual. 2011, 16, 169-185. [CrossRef]

30. Raghallaigh, M.N.; Gilligan, R. Active survival in the lives of unaccompanied minors: Coping strategies, resilience, and the relevance of religion. Child Fam. Soc. Work 2010, 15, 226-237. [CrossRef]

31. Faigin, C.; Pargament, K. Strengthened by spirit: Religion, spirituality, and resilience through adulthood and aging. In Resilience in Aging: Concepts, Research; Resnick, B., Gwyther, L., Roberto, K., Eds.; Springer: New York, NY, USA, 2010; pp. 163-180.

32. Manning, L. Enduring as Lived Experience: Exploring the Essence of Spiritual Resilience for Women in Late Life. J. Health Relig. 2014, 53, 352-362. [CrossRef] [PubMed]

33. Brodsky, A.E. The role of religion in the lives of resilient, urban, African American, single mothers. Commun. Psychol. 2000, 28, 199-219. [CrossRef]

34. Tarakeshwar, N.; Hansen, N.B.; Kochman, A.; Fox, A.; Sikkema, K.J. Resiliency among individuals with childhood sexual abuse and HIV: Perspectives on addressing sexual trauma. J. Trauma. Stress 2006, 19, 449-460. [CrossRef] [PubMed]

35. Trenholm, P.; Trent, J.; Compton, W.C. Negative religious conflict as a predictor of panic disorder. J. Clin. Psychol. 1998, 54, 59-65. [CrossRef]

36. Ellison, C.G.; Boardman, J.D.; Williams, D.R.; Jackson, J.S. Religious involvement, stress, and mental health: Findings from the 1995 Detroit area study. Soc. Forces 2001, 80, 215-249. [CrossRef]

37. Banerjee, M.; Pyles, L. Spirituality: A source of resilience for African American women in the era of welfare reform. J. Ethn. Cult. Divers. Soc. Work 2004, 13, 45-70. [CrossRef]

38. Greene, R.R. Resiliency: An Integrated Approach to Practice, Policy, and Research; NASW Press: Washington, DC, USA, 2002.

39. Chris, A. 'We don't do God': A critical retrospective of New Labour's approaches to 'religion or belief' and 'faith'. Cult. Relig. 2011, 12, 259-275.

40. Jochum, V.; Pratten, B.; Wilding, K. Faith and Voluntary Action: An Overview of Current Evidence and Debates; NCVO: London, UK, 2007.

41. Maton, K.I. Spirituality, religion and community psychology: Historical Perspectives, Positive Potential, and Challenges. J. Commun. Psychol. 2001, 29, 605-613. [CrossRef]

42. Bourke, B. Positionality: Reflecting on the Research Process. Qual. Rep. 2014, 19, 1-9.

43. Renzetti, C.M.; Lee, R.M. Researching Sensitive Topics; SAGE Publications: Newbury Park, CA, USA, 1993.

44. Bernard, H.R. Research Methods in Anthropology: Qualitative and Quantitative Methods; AltaMira Press: California, CA, USA, 2002.

45. Tongco, M.D.C. Purposive sampling as a tool for informant selection. Ethnobot. Res. Appl. 2007, 5, 147-158. [CrossRef]

46. Silove, D.; Steel, Z.; McGorry, P.; Mohan, P. Trauma exposure, postmigration stressors, and symptoms of anxiety, depression and posttraumatic stress in Tamil asylum seekers: Comparison with refugees and immigrants. Acta Psychiatr. Scand. 1998, 97, 175-181. [CrossRef] [PubMed]

47. Haberl, C.G. The Neo-Mandaic Dialect of Khorramshahr; Otto Harrassowitz GmbH \& Co.: Wiesbaden, Germany, 2009.

48. Nashi, S.; Bolender, J. The Plight of Iraq's Mandaeans and Honderich's Principle of Humanity. Politics 2009, 29, 93-99. [CrossRef]

49. Gardner, I. Review of Three Recently Published Studies on the Mandaeans. Relig. Hist. 2006, 30, $217-224$. [CrossRef] 
50. Nickerson, A.; Bryant, R.A.; Brooks, R.; Steel, Z.; Silove, D. Fear of Cultural Extinction and Psychopathology Among Mandaean Refugees: An Exploratory Path Analysis. Neurosci. Ther. 2009, 15, 227-236. [CrossRef] [PubMed]

51. Bhugra, D. Migration, distress and cultural identity. Br. Med. Bull. 2004, 69, 129-141. [CrossRef] [PubMed]

52. Pargament, K.I. The Psychology of Religion and Coping: Theory, Research, Practice; The Guilford Press: New York, NY, USA, 1997.

53. Green, M.; Elliott, M. Religion. Health, and Psychological Well-Being. J. Relig. Health 2010, 49, $149-163$. [CrossRef] [PubMed]

54. Chandi, F.; Ferrari, M. Spirituality and Resilience in Children of War in Sri Lanka. J. Spiritual. Ment. Health 2011, 13, 52-77.

55. Schweitzer, R.; Greenslade, J.; Kagee, A. Coping and resilience in refugees from the Sudan: A narrative account. Aust. N. Z. J. Psychiatry 2007, 41, 282-288. [CrossRef] [PubMed]

56. Cole, J. The New Racism in Europe: Sicilian Ethnography; Cambridge University Press: Cambridge, UK, 1997.

57. Romm, N. New Racism: Revisiting Researcher Accountabilities; Springer: London, UK, 2010.

58. Sniderman, P.M.; Piazza, T.; Tetlock, P.E.; Kendrick, A. The New Racism. Am. J. Political Sci. 1991, 35, $423-447$. [CrossRef]

59. Essed, P. Understanding Everyday Racism; SAGE: Newbury Park, CA, USA, 1991.

60. Dovidio, J.F.; Gaertner, S.L. Changes in the Nature and Expression of Racial Prejudice. In Opening Doors: Perspectives on Race Relations in Contemporary America; Knopke, H.J., Norrell, R.J., Rogers, R.W., Eds.; University of Alabama Press: Tuscaloosa, AL, USA, 1991; pp. 201-241.

61. Krieger, N. Racial and Gender Discrimination: Risk Factors for High Blood Pressure. Soc. Sci. Med. 1990, 30, 1273-1281. [CrossRef]

62. Ungar, M.A. Constructionist Discourse on Resilience: Multiple Contexts, Multiple Realities among At-Risk Children and Youth. Youth Soc. 2004, 35, 341-365. [CrossRef]

63. Pulvirenti, M.; Mason, G. Resilience and survival: Refugee women and violence. Curr. Issues Crim. Justice 2011, 23, 37-52. 